\title{
1. Low carbon futures for all? Strategic options for global availability of environmental technologies
}

\section{Keith Culver}

What role can IP rights play in securing equitable global access to essential technologies for response to the challenge of climate change? This chapter explores the geopolitical context of this question, and argues that the question is at best misplaced, and at worst, a costly red herring. This chapter argues that where the need and opportunity are greatest for climate change mitigation and adaptation, the technologies needed are not essential technologies, and further, the relevant non-essential technologies are most useful if they arrive in the company of supporting institutions and practices. If this argument is sound, it points the way to a global strategy for equitable technology access and implementation in which IP rights play a relatively small role. In this strategy, support for equitable access to needed climate change technologies and implementation techniques is not gained by IP-handling tactics. Rather, appropriate support is supplied by enabling countries in greatest need of climate technologies to access finance and technical knowhow for implementation of integrated suites of technologies and implementation practices some existing and some new. This argument will be supported by a reflection on the present and future context of climate change mitigation and adaptation, a context in which the increasingly urban global population is distributed in significantly asymmetric urban environments: the slow-growing, rapidly decarbonizing, relatively wealthy and relatively old cities of the global North, and the fast-growing, high-carbon, relatively poor and relatively new cities of the global South.

\subsection{WHY ARE WE ASKING OUR QUESTION?}

The fact of global climate change, whether anthropogenic or not, is now widely accepted by academics, governments, civil society organizations 
and, in many countries, individual citizens. ${ }^{1}$ The direction of debate has now shifted to the question of how we might best mitigate and adapt to climate change. In this new debate, a range of practical questions has risen to the forefront, focused on assessment of the urgency of mitigation and adaptation, and the priority of specific actions according to the place and population affected. These practical questions enable localization of what has been a global debate, and in turn enable growing recognition that the effects of climate change are distributed unevenly amongst places and populations whose readiness to face those effects is equally uneven.

It is now becoming clear that in at least the early days of climate change mitigation and adaptation, many of the worst effects will be experienced by the least well-off and least prepared. ${ }^{2}$ Here we arrive at the motivation of the question uniting the diverse contributors to this volume: what can be done to ensure equitable access to the means to mitigate and adapt to climate change? Still more specifically, given that a substantial part of climate change mitigation and adaptation will involve implementation of technologies, how might we ensure equitable access to those technologies, and in particular, those technologies whose use requires the permission of technology intellectual property (IP) owners, whose profit motive might tend to make those technologies inaccessible to those who need them most? Still further detail can be added to the set of questions, as other contributors engage the importance and nuance of those technologies captured under the legal term of art 'essential technologies'. What is important for the purposes of this contribution is to penetrate to the core of the motivation driving a question whose focus on IP should not distract us from our overarching concern: to identify effective means to ensure that technologies needed for response to climate change are available to all who need them. This motivation is, of course, familiar, as is the impulse to be extraordinarily watchful regarding the interaction between free markets and involuntary participants in those markets. In the context of developing country access to AIDS drugs, for example, scholars and activists have urged attention to the interaction of TRIPS, national patent regimes, compulsory licensing, and special pricing mechanisms. ${ }^{3}$ The example of arguably successful advocacy of new access regimes for HIV/AIDS drugs may be taken as an inspiration for action by scholars and activists seeking to assist equitable access to climate change technologies. Yet this inspiration should not be taken as more than that, for reasons to do with differences between what might be called the 'problem structure' of HIV/AIDS, and the problem structure of climate change. 


\subsection{PROBLEM STRUCTURE OF CLIMATE CHANGE: IS ANYTHING REALLY NEW UNDER THE SUN?}

Response to climate change has been dominated by two approaches. The first is the currently stalled attempt to develop a post-Kyoto global response. The second is a distributed, multilevel response whose diverse and changing elements cannot be easily summarized. Particularly salient representative efforts include those at the supra-national coordinative level of the European Union's Emissions Trading Scheme and the C40 Cities Climate Leadership Group ${ }^{4}$ various national-scope yet not statesponsored activities conducted by organizations such as associations of mayors, ${ }^{5}$ and further transboundary ${ }^{6}$ and regional ${ }^{7}$ responses typically most well-developed in the Global North. As earlier ambitions for a global approach seem increasingly unrealistic when measured against the urgent need for action, attention is increasingly focused on this distributed, multilevel or 'polycentric' approach. ${ }^{8}$ In this approach, individual actors and even communities of actors operating with limited resources may reasonably be tempted to frame the problem of climate change in ways familiar from prima facie analogous situations, and actors may be further tempted to redeploy tools used previously in those apparently analogous situations.

The response to the problem structure of HIV/AIDS is especially instructive in this context. As the HIV/AIDS pandemic struck Africa, calls for assistance from the Global North compelled deep and useful reflection on the role of technology transfer in equitable access to minimum standards of healthcare. This reflection was substantially enabled by the particular problem structure of HIV/AIDS. In summary terms, the problem of HIV/AIDS is the same everywhere: if your jurisdiction's population includes persons carrying the HIV virus, your jurisdiction has a public and private health problem to address. Fortunately, in the case of HIV/AIDS, while variations in the virus exist, the technical solution to the healthcare problem presented by HIV/AIDS is more or less universal: those limited means available for prevention and treatment are appropriate to treatment of all instances of the illness, and there are no effective alternatives to those limited means. In this problem context, a considerable difficulty is posed by the fact that ownership of the technical solution by some raises access difficulties for others - and in the case of HIV/AIDS treatments, a problem of price.

The problem structure of climate change is not like that of HIV/AIDS. Unlike HIV/AIDS, the problem of climate change is not neatly divisible into the basic logical and practical unit of the person, varying in number 
but sharing the same health condition. Rather, the problem of climate change affects everyone, even while present causal drivers of climate change are localized, with specific, localized effects at production sites and elsewhere. Climate change mitigation and adaptation activities must accordingly have both universal and highly locally-focused elements. And, more controversially and so the core of what must be discussed next, localized mitigation and adaptation solutions are typically not solely technological, and typically not held by some who can withhold solution access from others. Thus, changes to regimes for access to essential technologies, whether by pricing or revised transfer mechanisms or other tools, are likely to be solutions to a problem which doesn't exist. Relevant solutions are not solely technological, and those solutions are not unique. Thus, the HIV/AIDS response analogy is inappropriate, and the hope that the wealthy, technology-laden Global North might via improved legal tools write a 'technology cheque' to assist the Global South is simply misplaced. Climate change may indeed be a new problem, requiring a suite of bespoke solutions while work continues on global solutions.

A deeper explanation of the context of the problem structure of climate change will demonstrate more persuasively the plausibility of the argument sketched immediately above. The following sections attempt to show that the climate change challenge is different in the Global North and the Global South because of crucial asymmetries in the problem context in those situations. Understanding these asymmetries is key to understanding the relation of technology, technology transfer, intellectual property and knowledge management in marshalling effective and equitable response to climate change.

\subsection{TWO ASYMMETRIES AND A CONUNDRUM}

\subsubsection{Asymmetry in Problem Context: Urbanization in the Global North and the Global South}

The challenge of climate change is faced in an increasingly urban world. This trend and its global effects are widely recognized. As Anna Tibaijuka, Under-Secretary-General of the United Nations and Executive Director UN-HABITAT, observed in 2006: 
The 100 years from 1950 to 2050 will be remembered for the greatest social, cultural, economic and environmental transformation in history - the urbanization of humanity. With half of us now occupying urban space, the future of the human species is tied to the city. ${ }^{9}$

It might be said, in light of this, that the unit of human experience of climate change is and will be the city. There is, of course, no such general thing as 'the city'. Rather, there are particular cities with particular characteristics. There are, nonetheless, some troubling general trends in urbanization, giving rise to an important asymmetry distinguishing many cities of the Global North from many cities of the Global South: urbanization is occurring far more rapidly and intensively in the Global South.

As the United Nations Department of Economic and Social Affairs has observed, the global population is projected to grow from 6.829 billion today to 9.149 billion by $2050 .{ }^{10}$ At the same time, the population living in urban areas is projected to gain 2.9 billion, passing from 3.4 billion in 2009 to 6.3 billion 2050. Thus, the urban areas of the world are expected to absorb all the population growth expected over the next four decades while at the same time drawing in some of the rural population. ${ }^{11}$

Urban populations are thus forecast to go from comprising a little more than 50 per cent of global population today, to nearly 70 per cent of global population by 2050. While total populations in the Global North are predicted to grow from 900 million to around 1.1 billion, the bulk of those populations are already urbanized. Most new urban growth will be significantly concentrated in the Global South. The United Nations has observed that:

Furthermore, most of the population growth expected in urban areas will be concentrated in the cities and towns of the less developed regions. Asia, in particular, is projected to see its urban population increase by 1.7 billion, Africa by 0.8 billion, and Latin America and the Caribbean by 0.2 billion. Population growth is therefore becoming largely an urban phenomenon concentrated in the developing world. ${ }^{12}$

To this picture of a growing urban Global South and a relatively stable urban Global North, we must add a crucial observation regarding the kinds of cities expected to experience urban growth. United Nations data show the following:

The world urban population is not distributed evenly among cities of different sizes. Over half of the world's 3.4 billion urban dwellers (51.9 per cent) lived in cities or towns with fewer than half a million inhabitants. Such small cities account for 53.2 per cent of the urban population in the more developed 
regions and for 51.4 per cent of that in the less developed regions. Between 2009 and 2025, small urban centres with fewer than half a million inhabitants are expected to account for 45 per cent of the expected increase in the world urban population. ${ }^{13}$

The asymmetry in population growth is paralleled by an asymmetry in the climate change-readiness of cities expected to cope with that growth. Cities in the Global North face a complex challenge quite unlike the challenge faced by cities of the Global South. Cities in the Global North must support aging populations whose total size is increasing only gradually, and while that growth is occurring on geographic footprints which may need substantial environmental remediation efforts, the limited anticipated population growth allows those cities to reduce their ecological footprint by means including population densification and reduction of total geographic footprint. Perhaps more importantly, as the cities of the Global North approach these challenges and the fresh challenge of climate change mitigation and adaptation, they do so from a relatively privileged position.

While the need for implementation of climate change mitigation and adaptation strategies is urgent, that need arrives at a time when many cities are already faced with the need to at very least renew aging infrastructure. Thus, challenges driven by demographic change and the need for infrastructure renewal are in a sense synergistic with climate change challenges: climate change adds another dimension to already existing needs to renovate, and to integrate new technologies into older surroundings while renovating. Cities of the Global North have also had the luxury of knowing that a period of infrastructure renewal was in the offing, and as they approach that renewal, they further benefit from their relative wealth, and their knowhow regarding established urban governance processes reaching over geographic areas and city functions. ${ }^{14}$ It should be noted that the over-10 million population mega-cities of the Global North may be especially well-equipped to face climate change challenges, since they are in effect vortices of global and regional wealth and expertise, capable of generating sui generis solutions, while smaller cities lack similar means and need supplementary assistance from states or trans-state bodies. ${ }^{15}$

The luxuries of the cities of the Global North are in short supply in the cities of the Global South. In the Global South, even the older cities undergoing rapid growth have for the most part outstripped their capacity for regulated growth. ${ }^{16}$ While new growth offers in principle the opportunity to install latest-generation infrastructure, cost considerations and 
the speed of population and urban growth often overwhelm the opportunity, leaving city administrators facing slum-growth as their greatest problem. Indeed, whereas the cities of the Global North are able to 'renovate in place' in a highly controlled manner, cities of the Global South are coping with uncontrolled growth over geographic areas which may be highly unsuitable to urbanization. Far from well-considered and well-funded approaches to climate change mitigation and adaptation, cities of the Global South may be absorbed in slum upgrading projects, ${ }^{17}$ handling immediate problems prior to forecast problems. This observation should not be taken as a denial of the innovative capacity of cities of the Global South, especially those emerging mega-cities which are concentrating national talent and investment. Yet it is nonetheless an observation that, on balance, cities of the Global South face different, special challenges. Those challenges may be especially acute in smaller cities which lack both the special attractive capacity of mega-cities (which often function as high national champions, attracting and retaining resources), and the built-up multigenerational wealth of the smaller cities of the Global North.

\subsubsection{Asymmetry in Innovation Capacity Orientation}

A second, closely related asymmetry is evident in the orientation of innovation capacity in the Global North and Global South. Both poles face increasingly urgent effects of climate change. Yet variations in existing urban development and future development trajectories mean that IP-producing innovation capacity, efforts, and technology results are not well-focused on climate change problems of greatest importance to countries most in need of assistance in responding to climate change. Thus, action to support equitable access to certain technologies via special IP regimes is likely to be an effort made in vain. In what follows I shall try to explain this asserted asymmetry by showing that where climate change technologies are relevantly transferable from North to South, they are for the most part non-essential; and where arguably essential climate change technologies exist or might reasonably be foreseen to arise, they are essential to climate change actions of limited relevance, which in any case arrive with significant non-technical implementation challenges requiring further non-technical expertise and tools. What is needed to ensure equitable access to the means to relevant and sufficient climate change mitigation and adaptation is not specialized access to existing non-essential technologies. Rather, what is needed is improved global and local capacity for developing and implementing the 
customized solutions required, a challenge best framed in terms of knowledge mobilization rather than access.

The emergence of this asymmetry has been driven by a complex set of interacting factors. Perhaps the most important factor is the embeddedness of climate change in a broader problem context often spoken of as a 'nexus'. Whether a climate change-energy-water nexus, or a climate change-food-energy-water nexus, or some other combination, a set of interacting demand, supply and environmental quality challenges may stretch cities and problem response capacities to the limit. Sir John Beddington, Chief Scientific Adviser to the UK government, famously drew attention to this nexus with his 'perfect storm' address and paper. ${ }^{18}$ Still more famously, Beddington claims that the perfect storm of catastrophic interactions at the heart of the nexus might arrive much sooner than anticipated. Integrating evidence drawn from the United Nations, the OECD, the World Bank, and others, Beddington predicts that 'that by 2030 the world will need to produce 50 per cent more food and energy, together with 30 per cent more available fresh water, whilst mitigating and adapting to climate change'. ${ }^{19}$ Unsurprisingly, in light of previous discussion of an asymmetry in population growth and urbanization in the Global North and the Global South, increased demand for energy, food, and water will be concentrated in the Global South. Already, as of 2008, non-OECD countries consume more energy than OECD countries, led by growth of energy demand in India and China. ${ }^{20}$ And, Beddington observes, 'Energy demand is projected to increase by $45 \%$ between 2006 and 2030, based on the IEA's [2008] reference scenario. ${ }^{21}$ This situation calls not just for improvements in various practices around the nexus, but further, for rapid transformation of the way we produce and use food, water, and energy, all while mitigating and adapting to the effects of climate change.

Discussion above of the asymmetry in growth and growth-management capacity North and South can now be extended with an observation about the targets of urgent response to the nexus identified by Beddington. While we clearly face a multifaceted problem, it is worth focusing response efforts on reduction of greenhouse gas emissions. These emissions are harmful in their own right as contributors to climate change and effects as diverse as acidification of oceans and prolonged droughts, but further, emissions are associated with unsustainable reliance on increasingly scarce fossil fuel energy resources of certain kinds. This last claim requires extraordinarily careful treatment, in part because Hubbert curve arguments regarding 'peak oil' may be misleading as indications of availability of fossil fuels to the world economy, if conversion of energy 
use systems can accommodate use of relatively abundant natural gas, or 'clean' gasification of abundant coal supplies.

I aim to make a somewhat different point, not about resource supply and environmental consequences, but about speed of technology development and deployment relative to the urgency of the challenge faced. Emission reduction is usefully taken as a proxy for climate change adaptation and mitigation to the extent that emissions are associated with a suite of practices which are unsustainable in an asymmetrically urbanizing world. The World Resources Institute has published a justly famous chart making this connection (see Figure 1.1).

The chart in Figure 1.1 makes clear where in global terms the greatest gains are to be made, and indeed must be made, as we transition from fossil fuel dependence: in transport, electricity, and heat, including 18.5 per cent of total gas emissions attributable to heating, cooling, and other uses in residential and commercial buildings, and industrial uses, including the perhaps surprising 5 per cent of total emissions due to the cement industry. This picture is, however, changing rapidly as growth in the Global South drives emissions upward in specific sectors, as illustrated in Figure 1.2.

As the graph in Figure 1.2 makes clear, the rise in emissions is driven by non-OECD countries in sectors associated with rapid industrialization and economic growth: emissions from electricity and heat are rising rapidly, correlated with rising industrial energy use, while transportrelated and building use emissions are increasing much more slowly. As these data show, the greatest challenge in climate change mitigation and adaptation comes from energy generation and use, driven by rising demand concentrated in the Global South. It is worth noting in this context that while current summaries of emissions tend to be reported in terms of US, China, OECD, and non-OECD emissions, the rise of India is especially important within the non-OECD countries. India will soon warrant separate treatment in light of the volume of emissions from current and future sources in coal-fired power generation, discussed further below. As the US Energy Information Administration reported the trend in its 2010 report on energy-related carbon dioxide emissions:

In 1990, China and India together accounted for 13 percent of world carbon dioxide emissions; by 2007 their combined share had risen to 26 percent, largely because of their strong economic growth and increasing use of coal to provide energy for that growth. ${ }^{22}$ 


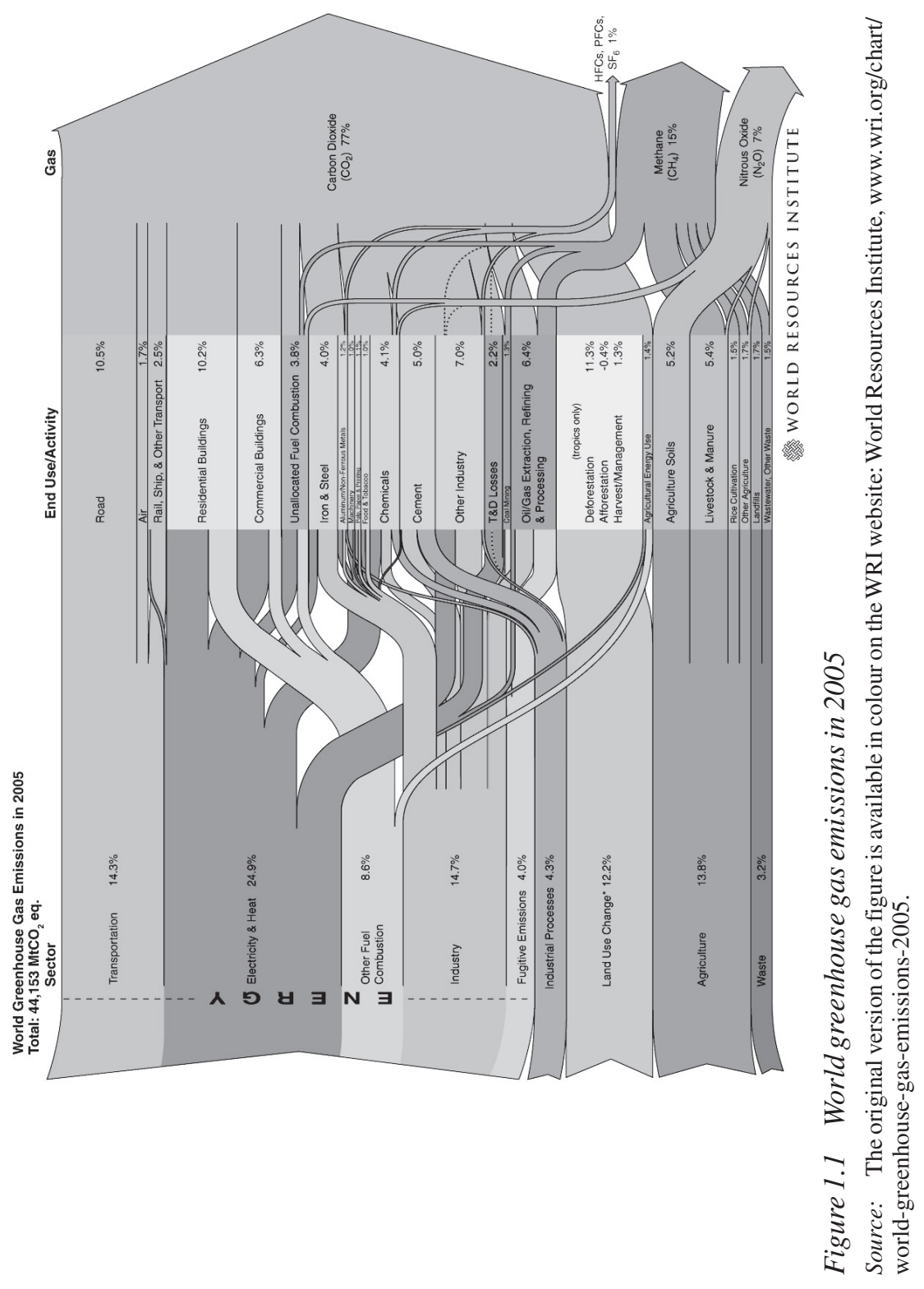




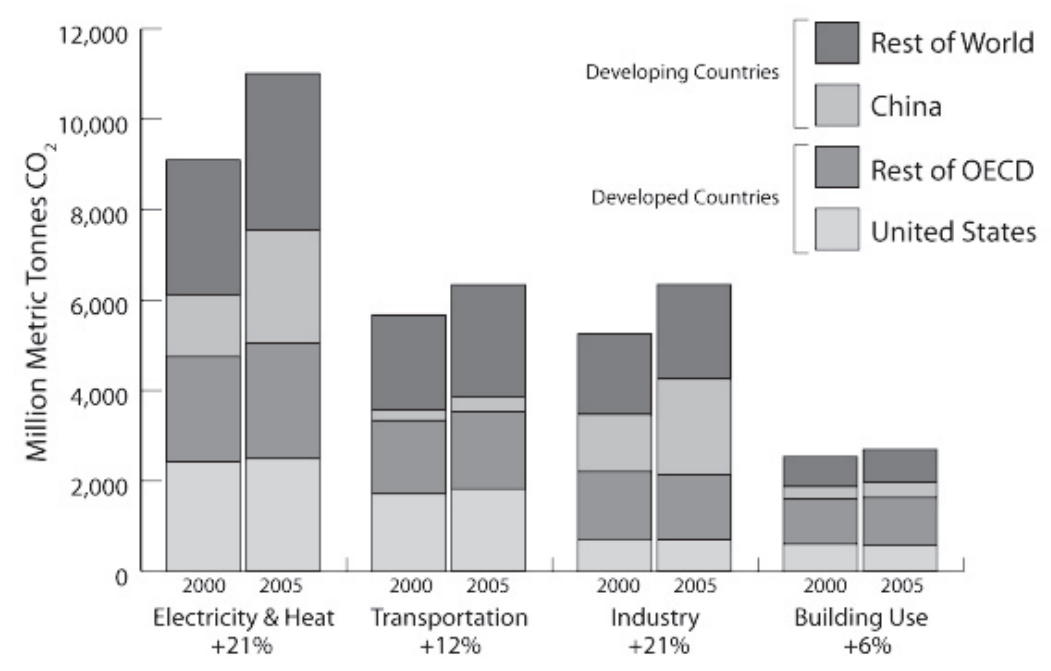

Figure 1.2 Global $\mathrm{CO}_{2}$ emissions growth in select sectors 2000-2005

Source: World Resources Institute, 31 July 2009, www.wri.org/chart/global-co2emissions-growth-select-sectors-2000-2005.

A number of approaches have been advocated to extract us from a potentially disastrous 'business as usual' scenario in which average global temperatures exceed the Intergovernmental Panel on Climate Change (IPCC)'s recommended 2 degree Celsius maximum rise by 2050 . The BLUE scenario, for example, is advanced by the International Energy Agency as an integrated policy and technology development approach identifying steps and timelines for combined Global North (principally OECD member countries) and Global South response to climate change challenges. Approaches vary in their proposed blend of technologies and actors, yet they are united in their recognition that while OECD countries must continue their decarbonization, the major climate change actors in the period to 2050 will be China and India. It is, unfortunately, no exaggeration to say that the fates of less-developed countries depend significantly on major efforts from China and India, together with continued efforts from OECD countries to reduce emissions and to implement suites of technologies and policies necessary to drive changes enabling us to avoid a perfect storm. 
The heart of the asymmetry between problem and $R \& D$ orientation arrives with the quite different kinds of major efforts which must be made from China's and India's quite different situations in the futures contemplated by BLUE and other scenarios. While India and China are plausibly identified as key sources of emissions growth, their trajectories differ significantly with respect to stage of industrialization, and potential sources of renewable energy. China is moving from a period of rapid industrialization to a period of consolidation and transformation of its energy use, from fossil fuel-based to renewables-intensive. This planned transition comes on the back of massive, unprecedented development of coal-fired power plants, whose emissions constitute a major contribution to total global emissions. Data from the International Energy Agency (IEA) demonstrate this trend, as shown in Figure 1.3.

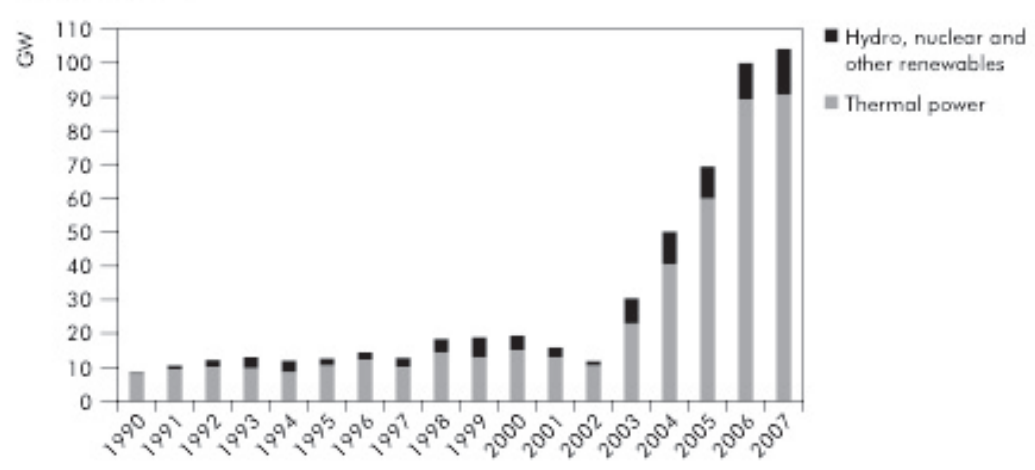

\section{Figure 1.3 Commissioning of new generation capacity for China}

Source: International Energy Agency, Energy Technology Perspectives: Scenarios and Strategies to 2050 (OECD/IEA, Paris, 2010) 386.

These new thermal power plants provide industrialized China with capacity to maintain base load while increasing the contribution of renewable energy sources, whose evident growth noted on the graph in Figure 1.3 is just the beginning of Chinese engagement with renewables. China is now the major global investor in non-fossil energy production, ${ }^{23}$ as China's growing economic strength is matched by increasing domestic capacity in research, development, and demonstration. Even as China's strategy is clear and in progress, it is at present highly reliant on coal. As the International Energy Agency reported: 
In 2007 total installed power capacity in China reached $718 \mathrm{GW}$, with 556 GW of almost entirely coal-based thermal power, $148 \mathrm{GW}$ of hydro-power, $8.8 \mathrm{GW}$ of nuclear power, $4.2 \mathrm{GW}$ of wind power and 0.86 of other renewable power generation. The country's reliance on coal for its electricity production, which accounted for $81 \%$ of total electricity generation in 2007 , means that the average $\mathrm{CO}_{2}$ intensity of its power generation is among the highest in the world at $777 \mathrm{~g} / \mathrm{kWh}$ compared to a world average of $507 \mathrm{~g} / \mathrm{kWh} .{ }^{24}$

It is unsurprising, then, that the International Energy Agency identifies clean coal technology and efficiency in energy use as major priorities for China, together with attention to efficiencies in energy distribution.

By contrast, India is also industrializing and is also heavily coaldependent, yet its domestic coal is of relatively poor quality and consequently Indian energy production from coal is especially emissionintensive. According to United States Energy Information Administration (EIA) estimates:

In India, 56 percent of the growth in coal consumption is expected to be in the electric power sector and most of the remainder in the industrial sector. In 2007, India's coal-fired power plants consumed 6.6 quadrillion Btu of coal, representing 65 percent of the country's total coal demand. ${ }^{25}$

According to the EIA's predictions for future coal use in India:

Coal use for electricity generation in India grows by 1.3 percent per year on average, to 9.5 quadrillion Btu in 2035, requiring an additional 51 gigawatts of coal-fired capacity (net of retirements). As a result, India's coal-fired generating capacity increases from 84 gigawatts in 2007 to 135 gigawatts in $2035 .{ }^{26}$

India, like China, is investing in renewables, but it is investing less, and it has a smaller installed base. So while China can fairly be said to have a predictable path from coal reliance to substantial integration of renewables, India is much further behind as there are more uncertainties regarding financing and implementation of suitable renewables. India's best course of action, according to the International Energy Agency, is to invest in carbon capture and sequestration to reduce the impact of its thermal generation, and to capitalize on its considerable potential for solar energy generation, all while improving the electricity grid which is still being expanded to electrify areas not yet electrified. ${ }^{27}$ This challenge must be taken on under circumstances of rapid growth in demand, a serious challenge even when some energy source transition is likely to be relatively easy, as in the case of solar where mature technology is available for implementation. As the International Energy Agency observed: 
Improved energy efficiency across both supply and end-use sectors is the single largest source of $\mathrm{CO}_{2}$ reductions. But even in the BLUE Map scenario, energy use in India still grows 2.5 times over the period to 2050. The challenge will therefore be to move to sources of energy and technologies that have much lower $\mathrm{CO}_{2}$ emissions than those used today and to achieve a near decarbonisation of the power sector. On a sectoral basis, the largest potentials for reducing $\mathrm{CO}_{2}$ emissions lie in the power generation and transport sectors, with $38 \%$ and $27 \%$ of the overall reductions in 2050 , respectively. ${ }^{28}$

And further:

For India to play its part in realizing the global goals of the BLUE Map scenario, it will need to achieve rapid economic development over the next 40 years with only a very small increase in $\mathrm{CO}_{2}$ emissions. Currently there is no precedent for such a low- $\mathrm{CO}_{2}$ development path. ${ }^{29}$

The near-term divergence of energy production and emissions trajectories in the Global North and Global South is striking. China and India continue to be heavily reliant on coal and need clean coal technology and carbon capture and sequestration technology to support emission reduction during the predicted period of continued industrialization, which will at length become less energy-intensive. At the same time the largely post-industrial Global North is decreasing reliance on coal ${ }^{30}$ while transitioning through what some are calling a 'golden age of natural gas' ${ }^{31}$ Relatively low-emission, high-efficiency natural gas power generation is regarded as a bridge to a low-carbon future in which multiple decentralized sources of renewable energy will feed into 'smart grids'. Smart grids will integrate and direct energy generation, transmission, storage and distribution to and from highly distributed 'prosumer' producers and consumers. ${ }^{32}$

In this context, the asymmetry between innovation capacity and direction in the Global North and Global South is stark even while it is multidimensional. At very least, it is fair to say that the most productive innovation systems in the world, those of the Global North, are challenged by the divergent emission-innovation demands of the coalintensive versus coal-reducing economies. More realistically, it is increasingly clear that the Global North does not have and is not focused on developing the technologies to which the Global South might request preferential access on equity grounds. Moreover, where the Global North does have relevant technologies, their implementation challenges at the scale required by reasonable emission-reduction scenarios lie largely in operational rather than access questions. 
On the technology development front, beginning with electricity generation, while the Global North is engaging in clean coal research, these efforts are at best incomplete, and inherently cleaner natural gas technology is being substituted for innovation in clean coal. As efforts stand, while there are some pilot projects, ${ }^{33}$ the IEA noted in 2010 that 'large commercial-scale CCS has not yet been applied to a coal-fired plant'. ${ }^{34}$ And while the Global North certainly has available smart grid technologies, those technologies are being developed for and trialled in quite different application situations. ${ }^{35}$ Smart grid technologies in the Global North are being deployed in relatively static cities in need of renovation in place, not the sprawling cities of the Global South. Yet, perhaps paradoxically, the slum-updating programmes of those cities might soon be accompanied by opportunities to electrify urban areas for the first time, installing along the way innovative smart grid technologies at a pace and level of innovation the highly-regulated, in-renovation Global North cannot match. These opportunities may arise as first Chinese then other Global South actors improve their innovation capacity, and as that innovation capacity enables those actors to partner meaningfully with technological and social innovators in the Global North to innovate in the relatively unconstrained urban environments of large and mid-sized cities of the Global South - but that opportunity is only latent, and must be made active, using approaches explored in the next section.

The suggestion that the Global South may be a future source of superior innovation is offered seriously and against a backdrop of growing evidence. For example, the Cleantech Group's Global Cleantech 100 report ranks the top cleantech firms as judged by a panel, and observes in the 2010 edition that three Chinese firms are now present in the top 100, where in 2009 there were none. South-South technology transfer is increasingly plausible, in light of China's emergence, as a practical option for innovation sufficient to face climate change. China's presence in the rankings is nonetheless modest, and Californian domination remains:

North America's share increased from $55 \%$ to $57 \%$ of the overall, AsiaPacific's from $3 \%$ to $7 \%$, at the expense of Europe and Israel, whose overall share declined form $42 \%$ to $37 \%$. The US, led by California, remains the dominant country, a reflection of its leadership and history in creating and growing, venture capital-funded, innovation-based, technology companies. ${ }^{36}$

The Cleantech Global 100 ranking is admittedly a reputational ranking gathering and integrating the subjective perspectives of experts regarding firms, yet it is all the more useful for that reason. The ranking is an 
investors' and risk-embracing actors' response to the question 'Which 100 of today's private cleantech companies are the most likely to make the most significant market impact over the next five to ten years?'. ${ }^{37}$ Emphasis on perceived likelihood of market impact illustrates the direction of near-term successful translation of $R \& D$ and investment into climate change technologies. As the list in Figure 1.4 indicates, leading innovators are focused far more on energy and resource efficiency than renewable energy.

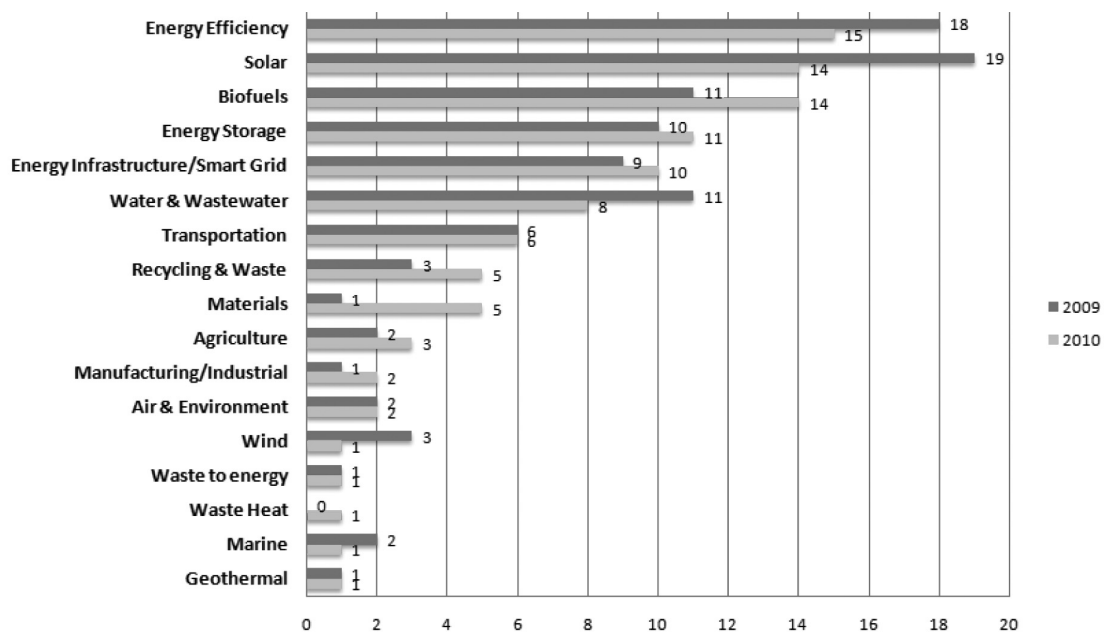

Figure 1.4 Sectors represented in Cleantech Global 100 in 2009 and 2010

The diversity evident among members of the top 100 bodes well for global efforts at diversification of energy sources for security of supply and price in light of anticipated price rises associated with predicted peak oil and scarcity of historically central energy sources. Yet viewed from a slightly different perspective of inquiry, this diversity is troubling. Even diverse efforts may be insufficient if they are not diverse in the right way. There is much that is laudable about the energy-efficiency orientation of these near-market cleantech leaders, but it is laudable primarily in the problem context of the Global North, well along the way to decarbonization and looking not just to a post-Kyoto world, but to post-carbon cities. These near-commercialization cleantech leaders are not, however, focused on the problem context of the Global South, and in particular, rapid development and unprecedentedly large-scale deployment of measures for emissions mitigation and adaptation in China and India. 
The asymmetry in problem structure and innovation focus should not, however, blind us to an important and potentially productive similarity between efforts in the North and in the South, which will underpin the solution to equitable climate change technology availability proposed in the final section of this chapter. The diversity of leading cleantech firms in the North illustrates the broad recognition that response to climate change requires innovation across multiple sectors and application domains. No one technology is key to any area of mitigation or adaptation - rather, technology mixes are evident, adapted to local circumstances, as Scotland embraces wind and eventually marine, while hot, arid Arizona is rather better suited to solar. To the extent, then, that the problem structure of climate change is amenable to a universal response, that universal response consists in the rapid deployment of diverse suites of technologies adapted to relatively local needs. Such technologies will necessarily and as a priority include 'clean coal' and carbon capture and sequestration, together with 'transition' fuels such as natural gas, and on to technologies supplying low-to-no carbon energy production, and technologies enabling adaptation to climate change through infrastructural and other non-energy technologies.

\subsection{THE CONUNDRUM AND TWO WAYS OUT}

The two asymmetries so far asserted lead us to a conundrum. If it is true, as argued, that the problem contexts of Global North and South are so different that the North's post-carbon innovation orientation is now of limited near-term relevance to the Global South, the question of how to use IP rights to ensure equitable access to essential climate change technologies seems rather misplaced. The technologies needed for rapid implementation by the South and its urbanizing, industrializing populations are likely to consist in suites or packages rather than individual technologies to which access might be readily blocked. Moreover, the individual technologies in these packages are often substitutable as, e.g., more than one type of wind or solar generator might be installed in a given situation, and implementation knowhow is non-rivalrous even while the challenges of rapid installation and scalability demand application of existing knowledge by skilful problem-solvers. Further, such knowledge and technologies are not in fact held by the Global North, so a relationship of inequitable access does not exist at the moment and seems unlikely, given innovation orientation trends, to arise in the near future. The question seems still more misplaced when it is recognized that China is now the global leader in both energy consumption ${ }^{38}$ and investment in 
renewables investment, ${ }^{39}$ and on some forecasts is thought to be ready to overtake the United States in scientific knowledge production as early as 2013. ${ }^{40}$

Here, we arrive at the conundrum generated by our two asymmetries: is there really anything the Global North can do to enable the Global South to acquire the climate change technologies it needs if the Global North is asymmetrically oriented toward the problem of climate change and major actors of the Global South seem perhaps better placed to approach their largest climate challenges? And is there a new or special role for intellectual property rights in this response, especially rights to essential technologies? It is worth taking seriously the possibility that the conundrum is evidence that we are rapidly exiting the era of 'development' in which transfer of knowledge is the means to enabling lessdeveloped countries to arrive at the state of development enjoyed by countries of the Global North. Recent growth in investment and innovation capacity in the Global South is not, however, any guarantee that China, or India, or other industrializing and modernizing countries can innovate fast enough and at the scale required to face leading problems in the form of emissions mitigation, and associated problems in both mitigation and adaptation.

The challenge remains shared and critical, and the imperative remains for the Global North to contribute to its resolution. That contribution's best form, however, may come less within the logic and practice of access and transfer, and more within the logic and practice of knowledge mobilization. A knowledge mobilization approach will recognize problem-solving capacity North and South, and inquire into how that capacity might be best organized and oriented toward a common problem with highly localized solution dimensions. Even while North and South face quite different problems in the speed and scale of changes needed, integration of approaches at multiple scales remains a common challenge. This common challenge is particularly acute in both technical and social dimensions of the global transition from high-carbon to low- or zerocarbon energy systems, even while the technical road-maps toward low-carbon economies are relatively well-established. The speed and scale of the required urban transformation poses what can be framed as a management and planning challenge, and the unprecedented magnitude of the challenge poses an innovation system challenge - we need not just innovation, but a faster method of innovating than ever before.

Crucially, both management and innovation strategies must be implemented in the context of technology road-maps which foresee a lowcarbon transition accompanied by a transition from interacting closed energy systems such as 'always on' electricity grids, to high-distributed 
systems of intermittent energy sources plausibly characterized as complex systems which are both adaptive and generators of unpredicted emergent phenomena. ${ }^{41}$ Elements of this transition variably include 'always on' coal-fired, natural gas or nuclear generators supplying a grid additionally and increasingly integrating locally distributed renewable energy sources. These microgeneration sources, such as solar panels, wind turbines and biomass/biogas-fuelled fuel cells and Stirling engines, are often privately owned and controlled, and are increasingly operated in conjunction with further system elements including 'smart meters' enabling users to monitor and choose how and when they use energy, and with remotely controllable, localized storage of energy in forms as diverse as inertial flywheels, and parked and plugged-in electric vehicles used as batteries. ${ }^{42}$ These elements operate in the varied physical grid structures, from the typically aging and overburdened infrastructure of the Global North, to situations in the Global South where electrification crucial to development has yet to arrive in many rural areas.

The greatest contributions the Global North might make to acceleration of emissions reduction and climate change mitigation and adaptation in this context may ultimately be predominantly social, enabling technical innovation appropriate to the problem context of the Global South. In the context of this volume's overriding concern with social mechanisms enabling response to climate change, two principal areas seem ripe for contribution from non-technical experts in the Global North: formation and implementation of standards enabling management of rapid deployment and scale-up of low-carbon, highly-distributed energy systems; and development of methods for accelerated collaborative North-South innovation standards formation and dissemination, and structured competition accelerating development of low-carbon energy systems. The second topic is possibly of greater academic interest and longer-term practical impact, yet the first is essential so also deserves attention.

Preceding discussion noted the multiple levels of governance engaged in climate change mitigation and action, employing a variety of formal and informal regulatory approaches. The diversity of these starting points is at least initially valuable as diverse kinds of regulatory experiment are enabled. Yet in the longer run, the highly-distributed, multiple-consumerand-producer nature of renewables-intensive smart grids will demand a robust, shared and adaptive set of guiding and governing norms. Such norms, yet to be devised, will enable integration and interoperation of systems whose operational effectiveness will be measured according to meaningfully comparable performance standards. Development of these standards faces significant challenges demanding the engagement of external regulatory experts in addition to public and private sector actors. 
While state-based standards development is encouraging development and deployment of renewables via a blend of incentives, taxes, performance-based standards, and so on, a new range of enabling norms is needed to guide deployment of the renewables-integrating energy grids of the future. A very significant effort is needed to drive adoption of common standards for information exchange, and physical infrastructure, to avoid the future energy network resembling something as patchwork and failure-prone as the current blend of systems resulting in the current need for transformers and plug adaptors wherever one goes. Specific areas of further standards research and development range from familiar questions regarding feed-in tariffs for distributed electricity generators, to privacy issues raised when 'prosumer' producers and consumers contribute to and use electricity from a smart grid, and in so doing create commercially valuable data regarding usage patterns.

Further issues are raised in the area of 'demand side management', as use of smart meters to track energy consumption at building and device level is also enabling so-called 'load shedding' where end-users or system administrators can programme devices to stop using electricity at certain times or in response to pricing signals. ${ }^{43}$ Controversy arises with the possibility that system administrators may do the choosing regarding temporary shut-down of devices, or in effect withdrawal of service. A related issue arises when the demand side becomes the supply side: when consumers are also capable of producing, storing and feeding energy back into the electricity grid. Discussion regarding feed-in tariffs is just the beginning of the debate regarding the role of 'prosumers' in highly decentralized energy systems of the future. Highly decentralized systems will be distributed in production, yet still relatively centralized in organization. New standards and practices will permit 'virtual power plants' to serve an aggregating and distributing function, receiving and processing signals from intermittent renewable energy producers in both large-scale commercial enterprises and smaller scale generation organized in groups or individual household units. The virtual power plants of the future will need standards for information signals from energy storage units such as batteries, hydraulic storage, and electric vehicles, all processed by the virtual power plant in conjunction with information arriving in a standardized form regarding weather forecasts and tide predictions, and forward and realtime market prices. Virtual power plants may seem to be largely technical constructions needing technical norms to guide their operation; yet there are additional equity concerns which are important in the Global North, and potentially of critical importance in the Global South. Operating in this fashion as aggregators and distributors, virtual power plants have the potential to control network 
access, conditions under which users will be shed as loads, and conditions under which users' contributions to the grid will be accepted whether as individual contributors at household level, or perhaps in other forms such as neighbourhoods or cooperatives or small cities united by type of generation. The technical structure of virtual power plants is a subject of ongoing investigation, and that investigation ought to be accompanied by investigation of the appropriate normative structure of those virtual power plants, in large part because the future of equitable access to energy prerequisite to development may depend on design and access considerations being adjusted to permit small local producers to participate in energy production and use in grids largely owned and maintained by much larger organizations, whether private or public sector operators. The normative questions surrounding operation of the grid extend further into its physical infrastructure, from enabling norms regarding zoning and insurance, to skills and training standards.

These standard-setting exercises provide important opportunities to refine approaches both North and South, as extension of electrification in areas of the Global South, such as India, provide 'green field' opportunities $^{44}$ for new approaches unconstrained by pre-existing regulatory webs of the kind evident in the Global North. Yet a far more important task for lawyers is evident in a prior challenge associated with the urgent need for speedy development and deployment of technologies targeted at emissions reduction and subsequent replacement of high-carbon with lowcarbon energy sources. Given the current lagging pace and the urgency of the situation, it may be insufficient to rely on business-as-usual statesubsidized innovation systems funding researchers and research collaborations at national and supra-national level, competing to identify solutions then protected and exploited using intellectual property rights. It would be unfair to characterize this situation as a free-for-all in which unfettered competition leads to winners and losers where the 'first past the post' captures the patent and the profit. Yet there is undoubtedly duplication of effort amongst nations, and lack of alignment of expertise to problems. There is, in a phrase, competition, where the urgency and complexity of the problem of energy technology integration likely demands more structured competition - the kind of competition legal scholars might be well-equipped to design.

Classic examples of structured R\&D competition are easily found. The Manhattan Project is perhaps most famous among them: an international collaboration hosted by the United States, generating the first atomic weapons and developing the technology for nuclear power. The productivity triumph of the Manhattan Project was recognized by Vannevar Bush and the committee tasked by President Roosevelt with identification 
of the next goals for the nation's post-war scientific capacity. Vannevar Bush proposed application of federally funded science to the "war on disease', a war which sadly lost priority to the Cold War, ${ }^{45}$ and the proxy Space Race which US President Obama has described in his 2011 State of the Union Address as analogous to the challenge of American transition to non-fossil fuel energies. ${ }^{46}$ In these and similar efforts, central government or sponsor funding attracts research efforts and structures competition and encourages collaboration amongst researchers who might otherwise choose different research priorities. More recently, various forms of structured competition have been employed at national, international, and other levels. Bi-national structured competition has occurred as, for example, organizations like Genome Canada have formed one-off bi-national collaborative relationships with Genome Espana for large-scale science competitions and investigation of questions beyond the reach of individual partners ${ }^{47}$ At the European supranational level, the European Space Agency coordinates space exploration efforts beyond the capacity of any single member country. It engages in structured competition to solicit the best integrated European projects to advance its mission, in competitions such as its Cosmic Vision 20152025 programme. ${ }^{48}$ At the international yet non-state level, the philanthropic Bill and Melinda Gates Foundation has sponsored the Grand Challenges in Global Health initiative, which has used competitions to gather and focus research excellence on infectious diseases whose greatest effects are experienced in the Global South. ${ }^{49}$

These and analogously framed efforts embody important advances in the method of innovation. They embody a solution-oriented, problemdriven approach which is highly sensitive to the actual problems and needs of end-users of research results. The problems they target are beyond or above the interests of single states, and beyond the innovative capacity of the individual nation-states participating in resolution of the targeted problems. The efforts of the Gates Foundation are of particular interest to North-South collaborations to the extent that the Gates Foundation advances a principle of 'global access' of funded research results, acknowledging use of intellectual property rights as exclusionary rights and insisting on use of those rights to permit a certain kind of access to results.

From Vannevar Bush's advocacy of a war on disease, to the Gates Foundation's targeted approach to infectious disease, structured competition models are inspiring to the extent that they use competition to foster excellence, and focus excellence on urgent problems within and without national borders. Yet these efforts still fall short of the standard required for a coordinated global response to local experience of climate 
change. Non-state-sponsored efforts in structured competition tend to be piecemeal, tackling what an organization such as the Gates Foundation is managerially confident of tackling, rather than engaging a problem in its entirety. Efforts started from and based in the Global North are notoriously liable to criticism that they are 'supply side heavy', with the bulk of knowledge production occurring in or within the control of actors in the Global North. Yet these familiar objections are not the most worrisome kinds of objections as we search for new ways to innovate, in the absence of coherent, urgent and comprehensive state-sponsored international action. Rather, what is most worrying in the context of an urgent need for a rapid $R \& D$ response to climate change is the absence of systematic aggregation of lessons learned, in North-South partnerships designed to enable organizational learning North and South and development of innovation capacity in the Global South. The twin demands of urgency and the need to overcome the asymmetry of problem contexts North and South requires an approach to innovation which demonstrably learns, integrates, and uses lessons learned in specific experiments, which requires integration of actors North and South to enable co-definition of R\&D problems across the asymmetries, and to further enable codevelopment of solutions across the asymmetries.

This challenge requires a different approach to climate change innovation, an approach which does not assume the availability of coordinated multistate sponsorship of problem definition and solution identification, and instead attempts to make a virtue out of the fragmented state of efforts to date. We may need to be more 'Manhattan Project-like' in our approach, even while the nature of our problem, the non-rivalrous quality of the knowledge implicated in its solution, and the need to publicize rather than privatize research results, makes incentive-setting structurally difficult. Incentive-setting may be especially difficult when private sector engagement is desirable in moving from prototype to pilot to roll-out and scale-up.

Here there is a job for academic lawyers, in concert with engineers and others, as the kind of structured competition likely to focus and accelerate efforts in integration of diverse low-carbon energy sources will involve an interweaving of public and private actors in the North and the South, with benefit sharing mechanisms equal to the diversity of the knowledge and partners assembled. What is needed is a method for structured competition which assembles a global network of expertise in technical and non-technical aspects of renewable and alternative energies, and focuses that network on specific problems in such a way that problems are solved and successful team configurations are recognized, enabling a triage amongst teams so proven 'winners' are supported 
further via privileged association with other leading groups, and other excellence-focusing mechanisms. In the absence of an international treaty regarding concrete steps toward climate change mitigation and adaptation (more than mere emissions limitations and clean development mechanisms amounting largely to subsidies) it is perhaps tempting to suppose that any activities will naturally fall back into familiar state-dominated processes in which the rich will stay rich and the poor will stay poor. This need not, however, be the future case.

It is not unrealistic to suggest that the context of the emergence of virtual biotechnology firms might serve as an inspiration for a new kind of distributed yet systematically aggregated and integrated kind of climate change R\&D. Virtual biotechnology firms have arisen most prominently in the context of drug development, where successes and failures are notoriously unpredictable, and even small players can without warning happen upon a potentially highly valuable development immediately creating the need to operate like a much larger player. Virtual firms are temporary assemblies of investors, managers, technology advances, operational R\&D expertise, marketing, and other traditional drug development firm functions, but with the difference that these components may be geographically distant from one another, and are not 'in it for the long haul'. Rather, they are corporate assemblies designed to serve short-term purposes which once achieved are disassembled and the parts are freed for use in other contexts. ${ }^{50}$ Reported advantages of this approach include financial efficiencies driven by a reduction of fixed costs, and operational speed and flexibility grounded in the firm's regrouping proven expertise specifically relevant to the virtual firm's core business. Gathering of purpose-specific expertise is also said to provide a stable workforce which is relatively easily managed. These advantages arrive with risks, however, which require ongoing expert management, from a potential lack of cohesion, focus and urgency due to the geographically and institutionally dispersed nature of the workforce. A final danger noted in the context of drug development is the potential for virtual firms to be too ephemeral, holding a very small portfolio of products which is ultimately too small to permit the firm to operate effectively in a business role as a supplier or partner. ${ }^{51}$

The strengths of the virtual biotech firm model are ideally suited to structured competition to generate climate change solutions in NorthSouth collaborations, ${ }^{52}$ and the greatest disadvantage of virtual firms in the context of biotech may well be an advantage in the context of urgent, systematic and aggregated response to climate change challenges. While actors of the Global North may hold a lead over actors of the Global South with respect to institutions and methods of technology and 
knowhow integration associated with decarbonization of energy production and transport, those leading actors are in danger of being paralyzed by the complexities of innovation in highly-regulated and institutionally complex situations of the Global North. The Global South offers in many places an opportunity to fundamentally rethink technology choices for low-carbon urban, peri-urban and rural economies and societies - with market opportunities for firms of the Global North seeking to develop new markets, and opportunities to re-export innovations developed in the South back to the North. In parts of India and Africa, for example, where solar or other local, off-grid energy sources power mobile telephony in places otherwise not yet electrified, there are opportunities for entirely new thinking about electricity grid structure and function. Current thinking in the Global North is arguably dominated by obstructive assumptions regarding electricity generation to support 'base load', assumptions closely associated with the past dominance of coal, natural gas and nuclear 'always on' generation to which renewables may be 'added' as a kind of system-intrusion or distortion. When thinking about a future of highly-distributed energy generation, storage and use, the nearly blank slate available in areas of developing countries provides a relatively history-free experimental opportunity far more likely to produce transformative innovation than the complex, history-dominated situations of the Global North. The countries and cities of the Global South are in this way tremendously valuable partners for the innovators of the Global North, whose experimental platform situations may have marketable value.

In this context, the greatest weakness of virtual firms - that these short-lived entities may proliferate together with small product portfolios creating an unnavigable soup of firms and innovations - may be a strength if a knowledge marketplace is structured to organize and use this otherwise too-diverse body of knowledge. The Clinton Climate Initiative ${ }^{53}$ and the World Bank's Strategic Climate Fund ${ }^{54}$ contain elements of a knowledge-brokering approach which may be valuable. This could be amplified to provide for more than a 'matchmaking' service between, e.g., researchers and pilot project opportunities in the South, and, e.g., finance actors, managers, and researchers in the North. Actors such as the Clinton Climate Initiative or coalitions of NGOs, universities, and private sector actors might serve as hosts of a North-South knowledge market enabling creation of virtual firms composed of partners North and South, and additionally set participation rules encouraging aggregative and systematic knowledge sharing and mobilization. A prerequisite to participation in the knowledge market might be, for example, regular contribution to an 
e-portfolio portraying a participating organization's knowledge assets and innovation system role and capacity.

A similar urgency- and aggregation-supporting prerequisite to participation might be agreement to a 'use it or lose it' policy regarding intellectual property generated in virtual firms - a policy requiring unused IP to be contributed back into a common pool for use by other virtual firms in a kind of 'global access' of the sort pioneered by the Gates Foundation. Admittedly, these suggestions are blends of familiar ideas, perhaps all the better for being familiar, but presented in a slightly different structure. More and better ideas ought to be sought and incorporated to drive development of appropriately localized suites of climate change mitigation and adaptation technologies and policies. What matters here, for this chapter, is not those specific suggestions, but the direction away from a rhetoric and practice of 'access' which tends unhelpfully to cast knowledge flows as a largely unidirectional matter, and further presumes a kind of symmetry between solutions of the Global North and problems of the Global South.

The approach just sketched is an initial, illustrative rather than conclusive attempt to show that we must, and how we might, overcome the current cycles of discussion mired in mistaken understanding of problem contexts North and South, asymmetries in problems and problem-solving capacity, and an urgency-sapping reliance on state-based implementation via consensus. In the approach sketched, using market pull rather than relying on a currently unavailable post-Kyoto treaty, catch-up work can begin immediately. And by seeking to solve problems of the Global North in the more flexible experimental environments available in the Global South, the Global North may generate climate change technology/ policy packages faster, with enduring benefits accruing to the Global South as pilot projects are located in and adapted to the needs of the South. Perhaps most importantly, by attempting to get beyond 'access', aiming at global problem co-definition and co-creation creating globally relevant innovations, we are at least aiming in the direction of creating a shared method of innovation generating both absorptive capacity and innovative capacity in the Global South. The challenge of climate change demands and deserves nothing less.

\section{NOTES}

1. Broadly recognized major steps in development of the current consensus include: early governmental notice of climate change via James Hansen's 23 June 1988 testimony before the US Senate Committee on Energy and Natural Resources, 'The 
greenhouse effect: impacts on current global temperature and regional heat waves'. This drew on J. Hansen et al., 'Global climate changes as forecast by Goddard Institute for Space Studies three-dimensional model' (1988) 93 J Geophys. Res. 9341; skepticism expressed in B. Lomborg, The Skeptical Environmentalist: Measuring the Real State of the World (Cambridge University Press, Cambridge, 2001) and rebutted by H. Friel, The Lomborg Deception: Setting the Record Straight About Global Warming (Yale University Press, New Haven, CT, 2010); Senator Al Gore Jr's popularizing, consciousness-raising 2006 film An Inconvenient Truth; and stateauthored recognition of the danger and challenge of climate change in N. Stern, The Economics of Climate Change: The Stern Review (Cambridge University Press, Cambridge, 2007). Particularly significant recent outputs from the well-characterized national and international institutions coordinating climate change analysis include the Intergovernmental Panel on Climate Change (IPCC) Assessment Reports including Climate Change 2007, available at www.ipcc.ch/publications_and_data/ publications_and_data.shtml and the World Bank, World Development Report 2010: Development and Climate Change, available at http://wdronline.worldbank.org/ worldbank/a/c.html/world_development_report_2010/abstract/WB.978-0-8213-79875.abstract.

2. See generally Stern, n. 1 above, Part II 'Impacts of climate change on growth and development' and World Development Report 2010, n. 1 above.

3. A useful survey may be found in D. Dionisio, L. Fabbri and D. Messeri, 'HIV drug policies and South markets: settling controversies' (2008) 5(5) Therapy 707.

4. EU Action Against Climate Change: The EU Emissions Trading Scheme (2008). See also http://ec.europa.eu/clima/policies/ets/index_en.htm. The C40 Cities Climate Leadership Group is partnering with the Clinton Climate Initiative on urban emissions reduction and efficiency initiatives, see www.c40cities.org/.

5. At the national level see, e.g., the US Conference of Mayors' Climate Protection Agreement, available at www.usmayors.org/climateprotection/.

6. At the transboundary level see, e.g., the collaboration among Canadian provinces and US states at www.westernclimateinitiative.org/.

7. At the regional, subnational and state level see, e.g., the Northeast US Regional Greenhouse Gas Initiative, available at http://rggi.org/home/; in California the Global Warming Solutions Act of 2006, Calif. Assembly Bill 32 supported by the California Air Resources Board cap and trade mechanisms, available at www.arb.ca.gov/cc/ ab32/ab32.htm; and carbon taxes at the Canadian provincial level in British Columbia, available at www.fin.gov.bc.ca/tbs/tp/climate/carbon_tax.htm.

8. See e.g., survey discussion, E. Ostrom, 'Nested externalities and polycentric institutions: must we wait for global solutions to climate change before taking action at other scales?' (2012) 49(2) Economic Theory 353, online, 6 August 2010, available atwww.springerlink.com/content/723452714082113q/fulltext.pdf. For broader discussion, see J.E. Aldy and R.N. Stavins (eds), Architectures for Agreement: Addressing Global Climate Change in the Post-Kyoto World (Cambridge University Press, Cambridge, 2007).

9. Anna Tibaijuka, Under-Secretary-General of the United Nations and Executive Director UN-HABITAT, in remarks at the third session of the World Urban Forum in Vancouver, Canada, 2006, available at www.unhabitat.org/downloads/docs/3420_ 29282_ED1.pdf.

10. United Nations Department of Economic and Social Affairs, Population Division, World Population 2008 Wallchart, available at www.un.org/esa/population/ unpop.htm.

11. United Nations Department of Economic and Social Affairs, Population Division, World Urbanization Prospects - The 2009 Revision: Highlights (United Nations, New York, 2010) 1. 
12. Ibid.

13. Ibid. 4 .

14. See generally A. Kreim, M. Arnold and A. Carlin (eds), Building Safer Cities: The Future of Disaster Risk (International Bank for Reconstruction and Development/ World Bank, Washington, DC, 2003).

15. The 'C40' cities, for example, as a body composed of large cities includes members who are both sufficiently large to chart their own climate change response courses, and to engage with others at an international level, see www.c40cities.org/.

16. See, e.g.,, P.G. Hall and U. Pfeiffer, Urban Future 21: A Global Agenda for 21st Century Cities (Routledge, London, 2000). As they explain (at 14), 'And in the cities of Latin America and Africa and Asia, the overwhelming problem is not urban growth in itself, but the fact that cities' administrations lack the will, the competence or the resources to manage that growth.'

17. See e.g., the UN HABITAT Participatory Slum Upgrading Programme, available at www.un-habitat.org/categories.asp?catid=592.

18. J. Beddington, Food Energy, Water and the Climate: A Perfect Storm of Global Events? (Government Office for Science, 2009), available at www.bis.gov.uk/goscience/news/speeches/the-perfect-storm.

19. Ibid. 1.

20. Note also that in 2010, China's total energy consumption exceeded that of the United States for the first time. See International Energy Agency, 'China overtakes the United States to become the world's largest energy consumer', 20 July 2010, available at www.iea.org/index_info.asp?id=1479.

21. Beddington, n. 18 above, at 3, citing IEA, World Energy Outlook 2008 (IEA, Paris, 2008).

22. United States Energy Information Administration, 'Energy-related carbon dioxide emissions' in International Energy Outlook 2010, available at www.eia.gov/oiaf/ieo/ emissions.html.

23. Ernst \& Young, Renewable Energy Country Attractiveness Indices (Iss. 29, May 2011) 15.

24. International Energy Agency, Energy Technology Perspectives: Scenarios and Strategies to 2050 (OECD/IEA, Paris, 2010) 384-5.

25. United States Energy Information Administration, 'Coal' in International Energy Outlook 2010, available at www.eia.gov/oiaf/ieo/coal.html.

26. Ibid.

27. IEA, Energy Technology Perspectives: Scenarios and Strategies to 2050, n. 24 above, at 453.

28. Ibid. 452 .

29. Ibid.

30. See e.g., the observation in the BP Energy Outlook 2030: 'Coal is in decline in the $\operatorname{OECD}(-1.2 \%$ p.a. $2010-30)$, but this is more than offset by growth in the non-OECD ( $2 \%$ p.a.). In China and India the phase of rapid consumption growth ends around 2020; elsewhere in the non-OECD coal continues to grow steadily' (at 61), available at www.bp.com/sectiongenericarticle800.do? categoryId $=9037134 \&$ contentId=7068677.

31. See e.g., BBC News, 'International Energy Agency says gas in golden age', 7 June 2011, available at www.bbc.co.uk/news/business-13677732.

32. See generally K. Culver et al., 'Challenges related to the management of energy and transportation infrastructures within the context of future eco-cities', World Energy Congress, Montreal/Quebec, Canada, 14 September 2010.

33. A total of 234 carbon capture and storage (CCS) projects of various kinds were listed as underway as of 2010, Global CCS Institute, The Global Status of CCS: 2010 (Global CCS Institute, Canberra, 2011) ch. 3, also available at www.globalccsinstitute.com/ 
global-status-ccs-2010. In 'Projects/Policy', Carbon Capture Journal, 6 May 2011, noted that Alstom Power's Mountaineer Project in New Haven, West Virginia, achieved effective operation at ten times the scale of previous pilots, see www.carboncapturejournal.com/displaynews.php?NewsID=784\&PHPSESSID=cg8v ops2bgfc6360956ua8ikf1.

34. IEA, Energy Technology Perspectives: Scenarios and Strategies to 2050, n. 24 above, at 625. It is also worth observing that 'large-scale integrated projects' (LSIPs) for CCS are predominantly located in the Global North. According to the Global CCS Institute, 'Most LSIPS are in developed countries (notably the United States, Europe, Canada and Australia), with a few in emerging markets such as China', The Global Status of CCS: 2010, n. 33 above, at 39.

35. For example, the first smart grid project in France was announced in June 2011, but is not yet built, in the Paris suburb of Issy, by a consortium including French construction giant Bouygues, and energy firm Alstom. See Alstom website, www.alstom.com/grid/smart-grid/projects/demonstration-projects/issy-grid-france, and also E. Delsoi, Un 'smartgrid' en test a Issy-les-Moulineaux (11 April 2012), available at www.usinenouvelle.com/article/un-smartgrid-en-test-a-issy-lesmoulineaux.N172443.

36. Cleantech Group, Global Cleantech 100 (Cleantech Group/Guardian, 2010) 1, available at http://info.cleantech.com/GlobalCleantech100Report.

37. Ibid. 2.

38. See IEA, 'China overtakes the United States to be the world's largest energy consumer', 20 July 2010, available at www.iea.org/index_info.asp?id=1479.

39. 'China, Germany move ahead as clean energy leaders', China Post, 30 March 2011, available at www.chinapost.com.tw/business/global-markets/2011/03/30/296 552/ China-Germany.htm, referring to the Pew Clean Energy programme.

40. See Royal Society, Knowledge, Networks and Nations, Final Report (28 March 2011), available at http://royalsociety.org/policy/reports/knowledge-networksnations/.

41. See generally G. Strbac, 'Demand side management: benefits and challenges' (2008) 36(12) Energy Policy 4419.

42. W. Kempton and J. Tomic, 'Vehicle-to-grid power implementation: from stabilizing the grid to supporting large-scale renewable energy' (2005) 44(1) Journal of Power Sources 280.

43. Large-scale piloting of load shedding began as early as the 2001 'LIPAedge' experiment on Long Island, in which the Long Island Power Authority company controlled residential air-conditioners for load shedding at time of peak electricity demand. See www.lipaedge.com/program_details.asp.

44. India's growth and use of renewables is significantly hampered by lack of a modern grid extended to all users. As Ernst \& Young report, 'India suffers from a chronic electricity shortage, aggravated by the lack of a robust nationwide electricity grid, making it difficult to harness renewable energy potential'. Ernst \& Young, 'Country Focus India' in Renewable Energy Country Attractiveness Indices (Iss. 29, May 2011) 21.

45. V. Bush, Science the Endless Frontier: A Report to the President by Vannevar Bush, Director of the Office of Scientific Research and Development, July 1945 (US Government Printing Office, Washington, DC, 1945), available at www.nsf.gov/od/ lpa/nsf50/vbush1945.htm.

46. See text of speech at www.whitehouse.gov/the-press-office/2011/01/25/remarkspresident-state-union-address.

47. See the list of collaborative projects, available at www.genomecanada.ca/en/portfolio/ research/genoma.aspx.

48. See details at http://sci.esa.int/science-e/www/object/index.cfm?fobjectid=48467. 
49. See www.gatesfoundation.org/global-health/Pages/grand-challenges-explorations. aspx.

50. S. Aldridge, 'Biotechs go virtual' (2010) 28 Nature Biotechnology 189.

51. J.L. Calcagno, A. Behbahani and S. Mojtahedian, 'Is it virtuous to be virtual? The VC viewpoint' (2009) 27 Nature Biotechnology 886 at 887.

52. For general remarks on new collaborative North-South models see N.M. Dahan et al., 'Corporate-NGO collaboration: co-creating new business models for developing markets' (2010) 43(2) Long Range Planning 326.

53. See www.clintonfoundation.org/main/our-work/by-initiative/clinton-climate-initiative/ about.html.

54. See www.climateinvestmentfunds.org/cif/node/3. 